\title{
How Can Microwave Observations at 23.8 GHz Help in Acquiring Water Vapor in the Atmosphere over Land?
}

\author{
Quanhua (Mark) Liu ${ }^{1, *}$, Changyong Cao ${ }^{1}\left({ }\right.$, Christopher Grassotti ${ }^{2}$ and Yong-Keun Lee ${ }^{2}$ \\ 1 NOAA/NESDIS Center for Satellite Applications and Research, College Park, MD 20740, USA; \\ changyong.cao@noaa.gov \\ 2 Earth System Science Interdisciplinary Center, Cooperative Institute for Satellite and Earth System Studies, \\ University of Maryland, College Park, MD 20740, USA; christopher.grassotti@noaa.gov (C.G.); \\ ylee1218@umd.edu (Y.-K.L.) \\ * Correspondence: quanhua.liu@noaa.gov
}

check for updates

Citation: Liu, Q.; Cao, C.; Grassotti, C.; Lee, Y.-K. How Can Microwave Observations at $23.8 \mathrm{GHz}$ Help in Acquiring Water Vapor in the Atmosphere over Land? Remote Sens. 2021, 13, 489. https://doi.org/ $10.3390 /$ rs13030489

Academic Editor: Domenico Cimini and Stefania Bonafoni

Received: 25 November 2020

Accepted: 27 January 2021

Published: 30 January 2021

Publisher's Note: MDPI stays neutral with regard to jurisdictional claims in published maps and institutional affiliations.

Copyright: (c) 2021 by the authors. Licensee MDPI, Basel, Switzerland This article is an open access article distributed under the terms and conditions of the Creative Commons Attribution (CC BY) license (https:// creativecommons.org/licenses/by/ $4.0 /)$.

\begin{abstract}
Due to concerns about radio frequency interference from emerging telecommunications technology, there have been intensive discussions on the changes to the international Radio Regulations around $24 \mathrm{GHz}$ at the recent World Radiocommunication Conference in 2019. Although the sensitivity to total precipitable water (TPW) at $23.8 \mathrm{GHz}$ over land is small, and in some cases close to zero, state-of-the-art retrieval systems with no dependence on real-time ancillary data (e.g., numerical weather prediction (NWP) model forecasts), such as the National Oceanic and Atmospheric Administration (NOAA) operational Microwave Integrated Retrieval System (MiRS), have been producing reliable TPW products over both ocean and land, which implies that the microwave channel at $23.8 \mathrm{GHz}$ is providing valuable information on TPW over land as well as over ocean. The contradiction between the zero or near-zero sensitivity and practical performance over land raises questions for the remote sensing community and public users of such data. In this study, we examine the underlying physics and include mathematical explanations, which address and clarify the apparent contradiction. The channel at $23.8 \mathrm{GHz}$ is a direct measurement and indispensable for its combined use with microwave temperature and moisture sounding channels.
\end{abstract}

Keywords: passive microwave sensors; $5 \mathrm{G}$ wireless business; radio frequency interference; total precipitable water

\section{Introduction}

Passive microwave observations from space provide unique information content about atmospheric temperature, water vapor, cloud liquid water, ice water content, precipitation (rain and snow fall rate), ocean water salinity, ocean surface wind, and soil moisture, as well as aid in the characterization of sea ice, snow, and land surfaces [1-3]. There are numerous satellites carrying passive microwave instruments observing Earth's surfaces and atmosphere.

Satellite and conventional observations are assimilated at numerical weather prediction centers for daily weather forecasting [4-6]. Passive microwave observations contribute around $30-40 \%$ of the overall improvement of short-range forecast skill and provide around 15-30\% of the total number observations assimilated [7-9]. English [8] studied the requirement for 23.6-24.0-GHz observations for weather forecasting and demonstrated the importance for acquiring water vapor information.

Passive microwave observations from space began with measurements of Venus' surface temperature during the Mariner-2 mission in 1962. Cosmos-243 in 1968 carried the first microwave radiometer to measure Earth's atmosphere and surface from space. It was followed by three passive microwave remote sensing research missions: the Electrically Scanning Microwave Radiometer (ESMR) with a single frequency at $19.35 \mathrm{GHz}$ and at single polarization on Nimbus-5 in 1972; ESMR operating with a single frequency at 
$37 \mathrm{GHz}$ in dual polarizations on Nimbus-6 in 1975; and five dual-polarization channels of the Scanning Multichannel Microwave Radiometer (SMMR) on Nimbus-7 in 1978. The TIROS-N satellite was the NOAA's (National Oceanic and Atmospheric Administration's) first operational satellite equipped with the Microwave Sounding Unit (MSU) designed for acquiring atmospheric temperature profiles. The U.S. Advanced Microwave Sounding Unit-A (AMSU-A) and B on NOAA-15 (since 2005, AMSU-B on follow-on satellites was replaced by the microwave humidity sounder (MHS)) was launched on 13th May 1998 and has been measuring atmosphere/surface for more than 21 years. Today, we have NOAA-15 AMSU-A/B, NOAA-18 AMSU-A+MHS, NOAA-19 AMSU-A+MHS, NASA Aqua AMSU-A, Suomi NPP and NOAA-20 Advanced Technology Microwave Sounder (ATMS), Advanced Microwave Scanning Radiometer-2 (AMSR-2), and AMSU-A+MHS on the European satellites Metop-A, B, and C. All these recent satellites contain radiometers with a channel situated at $23.8 \mathrm{GHz}$, whose main purpose is the estimation of atmospheric water vapor.

Currently, there are ongoing discussions within the government, academia, and industry about future $5 \mathrm{G}$ wireless technology that could potentially impact passive microwave remote sensing due to radio frequency interference (RFI). In September 2018, the European Center for Medium-Range Weather Forecasts (ECMWF) hosted a workshop on the role and value of microwave observations from space in numerical weather prediction (NWP) with the specific goal of providing detailed guidance on the potential socioeconomic value of microwave bands allocated to the Earth Exploration Satellite Service (EESS) [7]. Weather forecasting is important to daily life as well as to the economy and society [10]. The radio frequency interference workshop reported that the value of microwave humidity observations has increased from just a few percent of the total to over $20 \%$ of the total over the last decade; microwave temperature sounders also provide around $20 \%$ of all observation impact. NWP relies on accurate observational information when potentially high-impact weather systems are in an early stage of development, providing advanced warning and time to take necessary action [9].

As noted, most passive microwave sensors in space have a water vapor channel at 23.8 GHz. The proposed 5G wireless technology may use a frequency close to this, thus potentially contaminating the water vapor channel measurements at $23.8 \mathrm{GHz}$. There are significant concerns about the impact without the water vapor channel. Delegates to the 2019 World Radiocommunication Conference (WRC-19) in Egypt have reached a compromise on an out-of-band-emission (OOBE) limit in the $24-\mathrm{GHz}$ band to protect passive weather satellites in the adjacent spectrum [11]. Theoretical studies show high sensitivity of the measured brightness temperature at $23.8 \mathrm{GHz}$ to the total column of water vapor (also known total precipitable water (TPW)) over oceans, which can be clearly seen from images of the brightness temperatures. The importance of TPW is that it gives a forecaster an idea of the amount of moisture in the air. Severe weather events, such as supercell storms, lightning, and hail, are correlated with high TPW. However, the sensitivity over land is very small and even zero, typically less than $0.1 \mathrm{~K}$ for a change of TPW of $1 \mathrm{~mm}$, which implies that the sensitivity over land is too low to acquire TPW. However, statistical results reveal that retrieved TPW over land from ATMS could be significantly degraded without the ATMS channel 1 at $23.8 \mathrm{GHz}$, the explanation of which is not straightforward to the wireless industries as well as the general public. This paper clarifies the principle of using NOAA-20 ATMS channel 1 at $23.8 \mathrm{GHz}$ for acquiring water vapor in the atmosphere, particularly over land surfaces.

It should be pointed out that 23.8-GHz channel observations are mainly used at numerical weather prediction centers as well as in physical retrieval systems for cloud detections and water vapor profile retrievals. The TPW is the integration of the water vapor profile. The reason we focus on TPW is because TPW was a single variable discussed multiple times for $5 \mathrm{G}$ technology radio frequency interference. This short paper may serve as better physical understandings and a typical case study instead of comprehensive analysis. 


\section{Principle of Passive Microwave Remote Sensing from Space}

Passive microwave instruments onboard satellites may have up to two dozen bands (also called channels) for soundings and imaging [12]. The sounding channels are for vertical profiles of atmospheric temperatures and water vapor as well as clouds. The imaging channels are for surface parameters and integrated column values of atmospheric parameters. Passive microwave channels are selected based on the fundamental properties of the Earth and its atmosphere. In general, atmospheric opacity is low at low frequencies and increases at higher frequencies, due to water vapor absorption and also increased absorption and scattering by clouds and precipitation. There is a relatively weak water vapor absorption line at $22.235 \mathrm{GHz}$ and a strong water vapor absorption line at $183.31 \mathrm{GHz}$. The strongest water vapor absorption is at $183.31 \mathrm{GHz}$ and the absorption decreases away from the absorption line. Using multiple water vapor channels, the passive microwave sensor can acquire atmospheric water vapor at different heights. The weaker the absorption, the lower the atmospheric layers that can be observed. ATMS has five water vapor sounding channels at $183.31 \pm 7.0,183.31 \pm 4.5,183.31 \pm 3.0,183.31 \pm 1.8$, and $183.31 \pm 1.0 \mathrm{GHz}$ that are sensitive to water vapor between 100 and $800 \mathrm{hPa}$ in general. The channel at $183.31 \pm 7.0 \mathrm{GHz}$ can be sensitive to water vapor in the surface boundary layer. Over high latitudes, where TPW is very low, this sensitivity can extend to surface parameters, such as skin temperature and surface emissivity. ATMS channel 1 at $23.8 \mathrm{GHz}$ provides useful information about the total precipitable water vapor and water vapor in the surface boundary layer. Because of the higher scattering at ATMS channel $17(165 \mathrm{GHz})$ than channel $16(88 \mathrm{GHz})$, these channels can be used to characterize precipitating clouds, for example, rain vs. snow.

Multiple oxygen absorption lines are located between 50 and $60 \mathrm{GHz}$ (called the $60-\mathrm{GHz}$ band hereafter) and close to $118 \mathrm{GHz}$. The $60-\mathrm{GHz}$ band is less affected by clouds and wide enough to allow multiple channels to measure atmospheric temperature profiles. The 118-GHz oxygen absorption line cannot provide the same quality of information on temperatures as the oxygen absorption lines within $50-60 \mathrm{GHz}$, because the spectral absorption line is narrower and the effects of clouds are stronger than at the $60-\mathrm{GHz}$ band. However, because of the shorter wavelength, smaller fields of view can be achieved at $118 \mathrm{GHz}$, so it is of interest for small-scale features having a large amplitude, where ATMS has 13 channels within $50-60 \mathrm{GHz}$ for measuring the atmospheric temperature profile.

Microwave observations have good impact on the quality of the numerical weather prediction analyses (initial states) and forecasts because they can mostly measure temperatures above and below clouds, whereas infrared sensors have very limited capability in penetrating clouds. It has been shown that high-impact weather systems are often under cloudy conditions. Therefore, techniques that can provide information inside and below clouds are most valuable for NWP to capture newly developing weather systems. In addition, the radiation source function within microwave frequencies is a quasi-linear function of the temperature, which directly relates to the atmospheric or surface temperature.

Passive microwave measurement for a given channel onboard satellites depends on multiple atmospheric and surface parameters. For example, the brightness temperature of ATMS channel 1 at $23.8 \mathrm{GHz}$ depends on the atmospheric profiles of temperature and water vapor as well as the surface temperature and emissivity. Under cloudy conditions, it depends on the cloud water content as well. Sea surface emissivity is a function of the sea surface wind and sea surface temperature. Snow surface emissivity depends on snow density, depth, and grain size. The snow surface roughness and ice layer complicate the emissivity modelling. It is impossible to use a single channel to accurately derive geophysical parameters. ATMS uses 22 channels to simultaneously acquire information about surface parameters, atmospheric profiles of temperature and water vapor, as well as clouds. The NOAA Microwave Integrated Retrieval System (MiRS) utilizes the multiple channel measurements to derive the geophysical parameters simultaneously. The radiance assimilation systems at numerical prediction centers around the world utilize brightness temperatures from multiple microwave and infrared channels onboard various satellites 
and improve the initial state of geophysical parameters simultaneously. Radiance assimilation demands more computational resources than what we have. In this study, we use MiRS to study the impact of the ATMS channel 1 measurements on TPW retrievals.

\section{NOAA Microwave Integrated Retrieval System (MiRS)}

The NOAA Microwave Integrated Retrieval System (MiRS) system has been implemented operationally at the U.S. National Oceanic and Atmospheric Administration since 2007 and has been generating many environmental data records (i.e., satellite products) for NOAA-18, NOAA-19, SNPP ATMS, NOAA-20 ATMS, Metop-B and C, SSMIS, AMSR-2, and GMI. The satellite products are atmospheric profiles of temperature and water vapor, cloud liquid water, ice water content, rainfall rate, snow cover and snow water equivalent, snow fall rate, surface temperature and microwave emissivity, and sea ice concentration (https:/ / www.star.nesdis.noaa.gov/mirs/highresolutionv.php).

The MiRS is based on the 1D-VAR retrieval algorithm [1,2], which includes the community radiative transfer model (CRTM) for computing radiances and the gradient of radiance (or Jacobian) [13], and a scheme for minimizing the cost function that weighs the relative contribution of background (a priori) information and satellite observations. Assuming that the errors in the observations and in the a priori information are neither biased nor correlated, and have Gaussian distributions, the best estimate will minimize the cost function:

$$
J(x)=\left[\frac{1}{2}\left(x-x_{0}\right) \times B^{-1}\left(x-x_{0}\right)\right]+\left[\frac{1}{2}\left(Y_{m}-H(x)\right) \times E^{-1}\left(Y_{m}-H(x)\right)\right]
$$

where $x$ is a retrieved state vector. The state vector may include the temperature, water vapor, and cloud water contents at each atmospheric layer. The first item on the right represents the penalty for departing from the background $x_{0}$ (a priori). The departure is weighted by the error covariance matrix $B^{-1}$. The diagonal elements of $B^{-1}$ are the standard deviations of the state variables while the off-diagonal elements are error correlations among state variables, for example, between the temperature and water vapor profiles. The second term represents the penalty for the simulated radiances $H(x)$ (or brightness temperatures) departing from the observed radiances (or brightness temperatures) $Y_{m}$, weighted by the sum of the instrument and forward modeling errors $E^{-1} . H$ is a forward operator.

The minimum of the cost function may be found from an iterative process. It computes descent directions that are gradients of the cost function (Equation 1) to the state vector $x$ :

$$
\nabla_{x} J(x)=B^{-1}\left(x-x_{0}\right)-K^{T}(x) E^{-1}\left(Y_{m}-H(x)\right)
$$

where $K^{T}(x)$ the adjoint model, which is equivalent to the transpose of radiance Jacobian with respect to the state vector. Using the first Taylor expansion:

$$
H(x)=H\left(x_{0}\right)+K(x)\left(x-x_{0}\right)
$$

By inserting Equation (3) into Equation (2) and letting Equation (2) equal to zero (where the cost function $J(x)$ will have a local minimum), we obtain:

$$
\left(x-x_{0}\right)=\left[B^{-1}+K^{T}(x) E^{-1} K(x)\right]^{-1} K^{T}(x) E^{-1}\left(Y_{m}-H\left(x_{0}\right)\right)
$$

Equation (4) may be solved in an iterative process. It is an iterative physical inversion system that finds a consistent geophysical solution to fit all radiometric measurements simultaneously. One of the particularities of the system is its applicability in cloudy and precipitating conditions. In order to be generic, the MiRS system adds a state vector for surface emissivity to automatically consider various surface properties. The inclusion of the emissivity spectrum in the state vector makes the system applicable globally, with the only differences between land, ocean, sea ice, and snow backgrounds residing in the covariance matrix chosen to spectrally constrain the emissivity. Similarly, the inclusion 
of the cloud and hydrometeor parameters within the inverted state vector makes the assimilation/inversion of cloudy and rainy radiances possible, and therefore, it provides an all-weather capability to the system. Furthermore, MiRS is highly flexible, and it could be used as a retrieval tool (independent of numerical weather prediction) or as an assimilation system when combined with a forecast field used as a first guess and/or background.

\section{Retrieval of Atmospheric Water Vapor}

In the MiRS system, all state variables, for example, atmospheric profiles of temperature, water vapor, and cloud water contents, are retrieved simultaneously by utilizing brightness temperatures from all of the channels. In the following, we focus on the ATMS applications. The same as the MiRS operational setting, the latitude/longitude-dependent climatological background is used as the a priori background as well as the first guess in the retrieval. ATMS channel 1,2, and 16, 17 are often called window channels that contain information about total precipitable water (TPW), clouds, and surface parameters, including surface emissivity. ATMS channels 3 to 15 are used for retrieving the atmospheric profile of temperatures. Together with ATMS channel 1, ATMS channels 18 to 22 are used for acquiring the atmospheric profile of water vapor. To avoid saturation for a very high water vapor amount, ATMS channel 1 is centered at $23.8 \mathrm{GHz}$ instead of at the water vapor absorption line at 22.235 GHz. ATMS channel 2 at $31.4 \mathrm{GHz}$ is less affected by water vapor but more sensitive to cloud liquid water. A simple radiative transfer equation may be helpful to understand what signals the passive microwave sensor receives from space. In the absence of precipitation (or insignificant scatterings in microwave), a radiative transfer equation is composed of upward surface radiation and upward atmospheric radiation as well as downward atmospheric radiation reflected upward from the surface. The equation may be expressed as:

$$
R=\varepsilon B\left(T_{\text {surface }}\right) \tau(\mathrm{atm})+R_{\text {up }}(\mathrm{atm})+(1-\varepsilon) \tau(\mathrm{atm}) R_{\text {down }}(\mathrm{atm})
$$

where $\varepsilon$ is the surface emissivity; $B\left(T_{\text {surface }}\right)$ is the Planck radiation at the surface temperature, $\tau(\mathrm{atm})$ is the atmospheric transmittance at the satellite height, and $R_{u p}(\mathrm{~atm})$ and $R_{\text {down }}(\mathrm{atm})$ are the upward atmospheric radiation at the satellite height and downwelling atmospheric radiation at Earth's surface, respectively. The radiance can be converted into the brightness temperature [14], which is commonly used in satellite data assimilation and in the retrieval of geophysical parameters. We also use the brightness temperature in the following equations.

Table 1 shows the sensitivity of the ATMS channel 1 brightness temperature $\left(T_{b}\right)$ on TPW $(W)$ at a sensor scan angle of 30 degrees for standard atmospheres. The surface emissivity values are given in the second row. The ocean surface emissivity value is the CRTM model calculated for a sea surface wind speed of $7 \mathrm{~m} / \mathrm{s}$ at $10 \mathrm{~m}$ above water. We choose U.S. standard atmosphere (low TPW), a mid-latitude atmosphere (close to global mean TPW), and a tropic atmosphere (high TPW). Over water, the sensitivity is very high because of low surface emissivity and high atmospheric emission. Over land, surface emission is dominant and the sensitivity to atmospheric TPW becomes weak. For high land surface emissivity, the sensitivity can become zero or negative. In general, the higher the sensitivity to a parameter, the better it is for acquiring the parameter. If only channel 1 is used, the perturbation of $T_{b}$ may be expressed as:

$$
\Delta T_{b}(1)=\frac{\partial T_{b}(1)}{\partial \log (W)} \Delta \log (W)
$$

where $W$ denotes the TPW. Thus, the TPW increment may be calculated as:

$$
\Delta \log (W)=\Delta T_{b}(1) /\left(\frac{\partial T_{b}(1)}{\partial \log (W)}\right)
$$


Table 1. ATMS channel 1 brightness temperature sensitivity to total precipitable water $(\mathrm{K} / \mathrm{mm})$ for the U.S. standard atmospheric profile [15], mid-latitude summer and tropical atmospheric profiles. The values in the second row are ocean surface emissivity, and three land surface emissivities (unitless). The values between the second and the fifth columns, and between the third and the fifth rows are the brightness temperature sensitivity on TPW in unit of $\mathrm{K} / \mathrm{mm}$. For example, for the case of U.S. standard atmosphere over ocean here, one millimeter water vapor increment will result in a $1.4333 \mathrm{~K}$ increase on the ATMS channel 1 brightness temperature.

\begin{tabular}{ccccc}
\hline & Ocean & \multicolumn{3}{c}{ Land } \\
\hline Atmosphere $\backslash$ Emissivity & 0.45470 & 0.93000 & 0.971905 & 1.00000 \\
\hline US Standard $(\mathrm{TPW}=14.2 \mathrm{~mm})$ & 1.4333 & 0.1146 & -0.0013 & -0.0796 \\
\hline Mid-latitude Summer $(\mathrm{TPW}=29.2 \mathrm{~mm})$ & 1.2492 & 0.1142 & 0.0133 & -0.0541 \\
\hline Tropic $(\mathrm{TPW}=41.1 \mathrm{~mm})$ & 1.0870 & 0.0877 & 0.0000 & -0.0593 \\
\hline
\end{tabular}

In the retrieval, the water vapor Jacobian is often expressed as the sensitivity of the brightness temperature to a logarithm of water vapor because water vapor exponentially decreases as height increase in the troposphere in general. Obviously, Equation 7 is singular when the water vapor Jacobian equals zero. The solution is unstable or has a large error for a very weak sensitivity.

Therefore, using single-channel information, the microwave measurement at $23.8 \mathrm{GHz}$ is not very helpful for estimating TPW over land. Figure 1 displays the water vapor Jacobian for ATMS water vapor channels 1, 18, 19,20,21, and 22 at a scan angle of 30 degrees for a tropical standard atmosphere over land. The land surface emissivity of 0.971905 is chosen for obtaining a zero sensitivity on TPW at $23.8 \mathrm{GHz}$. The emissivity value is typical for vegetated land and forest $[16,17]$. As one can see from the figure, the water vapor Jacobian for the ATMS channels 18 to 22 is negative because atmospheric emission is less than surface emission over the land for those channels. Similar to ATMS channels 18 to 22, the water vapor Jacobian for the ATMS channel 1 is negative above $820 \mathrm{hPa}$ (red dashed line). However, the Jacobian for the ATMS channel 1 is positive below $820 \mathrm{hPa}$, where atmospheric emission is higher than the surface emission over the land because the land surface emissivity is less than one. The surface emission for the emissivity of 0.971905 and a surface temperature of $299.74 \mathrm{~K}$ is equivalent to the emission of a blackbody at a temperature of $293.30 \mathrm{~K}$ since from the surface, reflected atmospheric downwelling radiation under a clear-sky condition is small for the window channel at $23.8 \mathrm{GHz}$. The Jacobian value itself at each layer for ATMS channel 1 is meaningful and significant, in particular the good sensitivity in the surface boundary layer. Basically, the sum of the Jacobian values above and below $820 \mathrm{hPa}$ is zero, which prevents one from deriving TPW via a method like Equation 7 using a single channel. Figure 1 shows that channel 1 has good sensitivity to a surface boundary layer while channel $18(183.317 \mathrm{GHz})$ has very good sensitivity to the middle and upper troposphere.

Figure 2 shows a case from an operational MiRS retrieval compared with an experimental retrieval performed without ATMS channel 1. It is for a single ECMWF profile. There is no obvious change in the temperature retrieval between the two experiments. However, without channel 1, the water vapor retrieval in the lower troposphere is significantly degraded, which affects the TPW retrieval. Table 2 shows the global statistics of the MiRS TPW retrieval against ECMWF analyses. We use the same operational settings and ATMS measurements in the MiRS for this study except for the switch on or off of the ATMS channel 1. The TPW derived from the ECMWF analysis data serves as the reference. In the operational MiRS retrieval, both the background and the first guess are interpolated by time and location from a dynamic climatological data set. The dynamic climatological data set was calculated from 60 days ( 5 days per month) of ECMWF data in 2015 and averaged for 5 (latitude) by 5 (longitude) degrees grids using a 10 by 10 degrees and 5-day moving window. In the ECMWF analysis, model prediction data and observations data 
are assimilated so that the analysis can serve as the "best" global reference. Over oceans, the degradation by removing channel 1 is more than $20 \%$ in standard deviation. Over land, a more than $12 \%$ degradation is observed. Table 3 shows the comparison over the Continental United States (CONUS) for the 5G RFI study. The degradation in TPW retrieval without channel 1 is more than $15 \%$ over land within the CONUS. The global results for 15 March and 26 April 2019 are very similar. So are the results over the Continental United States. We also checked the MiRS retrieval results using SNPP ATMS for 25 March 2019. The retrieved results for all three days are consistent. It needs to be pointed out that "Sea" in Table 3 only represents a small portion of the Atlantic and Pacific adjacent to land and water inland.

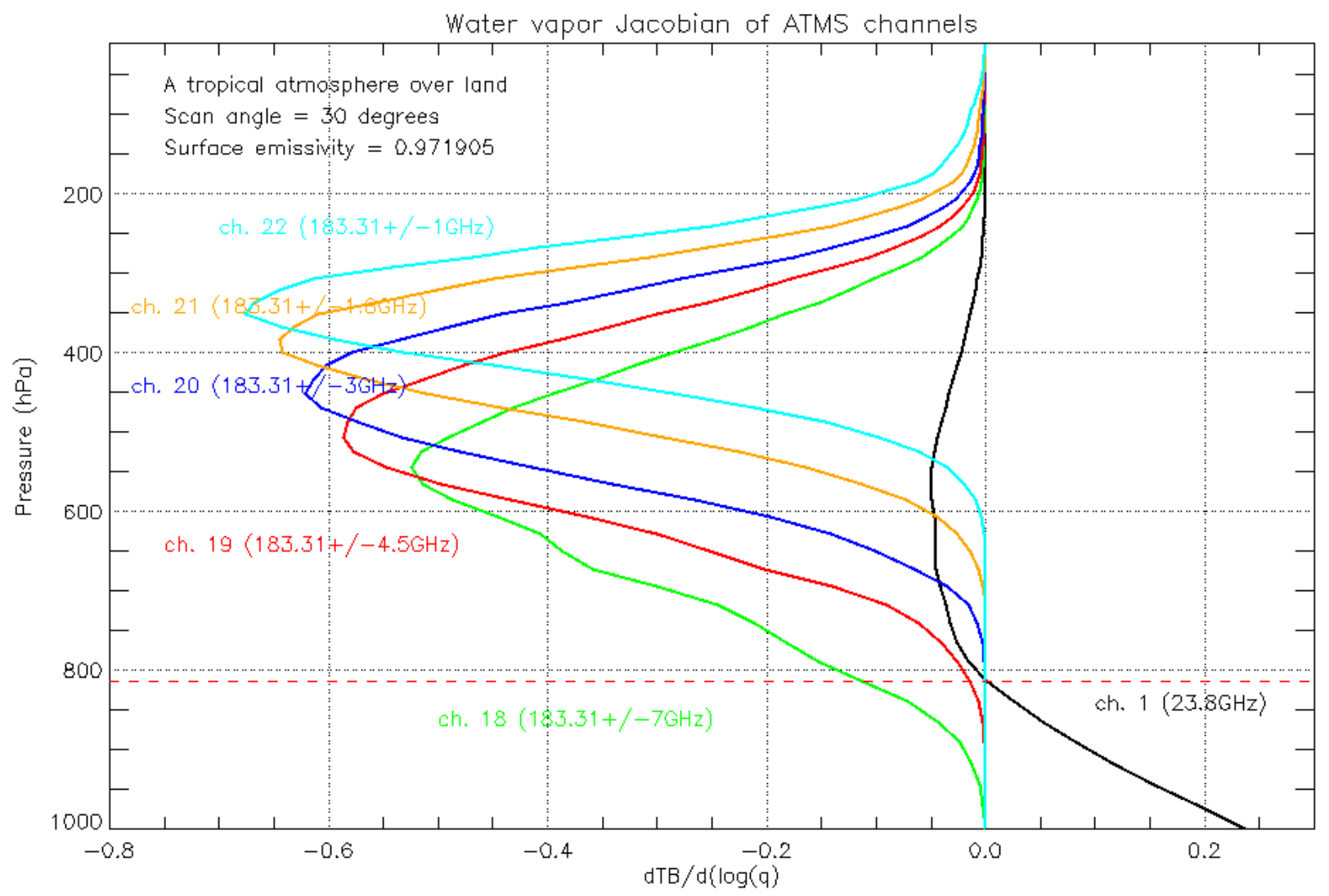

Figure 1. The sensitivities of the ATMS water vapor channels (1, 18 to 22) to an atmospheric profile of water vapor. The land surface emissivity of 0.971905 is chosen for all channels.

Table 2. Comparisons of MiRS retrieved global total precipitable water $(\mathrm{mm})$ between using all NOAA-20 ATMS channel measurements (operational) and ATMS measurements without channel 1 for March 15, 2019. The values in the red color are the relative change in the percentage of standard deviation ((std_ch1off-std_all_channel)/std_all_channel).

\begin{tabular}{cccccccccc}
\hline & \multicolumn{3}{c}{ All ATMS Channels } & \multicolumn{3}{c}{ ATMS without Channel 1 } \\
\hline & \multicolumn{2}{c}{ Clear } & \multicolumn{2}{c}{ Cloudy } & \multicolumn{2}{c}{ Clear } & \multicolumn{2}{c}{ Cloudy } \\
\hline & Land & Sea & Land & Sea & Land & Sea & Land & Sea \\
\hline Bias & 0.099 & 1.687 & 1.646 & 1.286 & 0.482 & 1.942 & 2.467 & 0.870 \\
\hline \multirow{2}{*}{ Standard deviation } & 2.634 & \multirow{2}{*}{1.874} & 2.689 & 2.275 & $\begin{array}{c}2.955 \\
(12.1 \%)\end{array}$ & $\begin{array}{c}2.291 \\
(22.2 \%)\end{array}$ & $\begin{array}{c}3.044 \\
(13.2 \%)\end{array}$ & $\begin{array}{c}3.314 \\
(45.6 \%)\end{array}$ \\
\hline
\end{tabular}



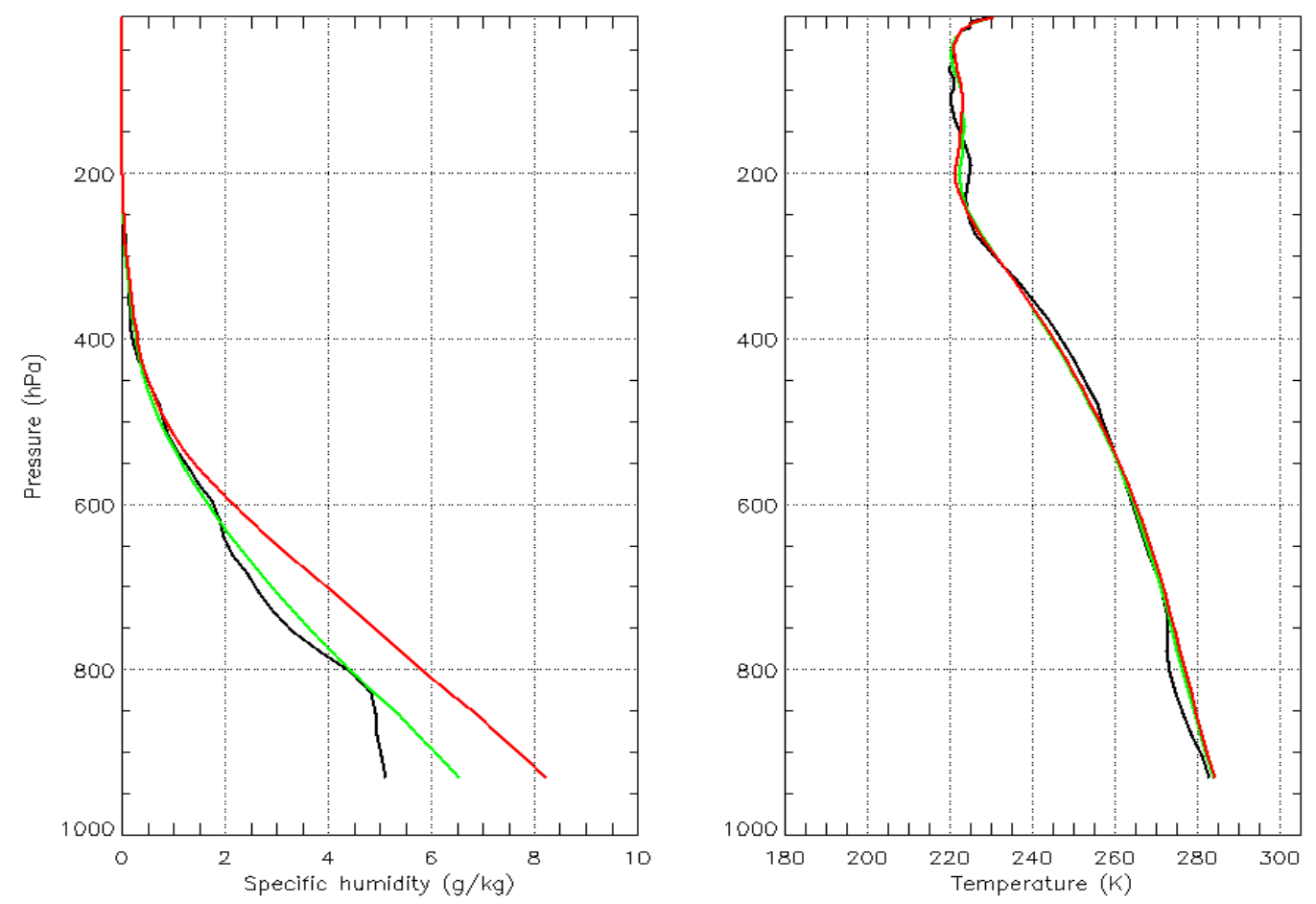

Figure 2. A case of a MiRS ATMS operational product. The black line is the ECMWF data (reference). The green line is the operational MiRS retrieval and the red line is the MiRS experimental test without ATMS channel 1.

Table 3. Same as Table 2, but for April 26, 2019 over the Continental United States.

\begin{tabular}{cccccccccc}
\hline & \multicolumn{3}{c}{ All ATMS Channels } & \multicolumn{3}{c}{ ATMS Without Channel 1 } \\
\hline & \multicolumn{2}{c}{ Clear } & \multicolumn{2}{c}{ Cloudy } & \multicolumn{2}{c}{ Clear } & \multicolumn{2}{c}{ Cloudy } \\
\hline & Land & Sea & Land & Sea & Land & Sea & Land & Sea \\
\hline Bias & 1.065 & 1.690 & 1.880 & 0.780 & 1.505 & 2.380 & 3.465 & 0.800 \\
\hline \multirow{2}{*}{ Standard deviation } & \multirow{2}{*}{3.338} & 2.225 & \multirow{2}{*}{3.178} & 2.433 & $\begin{array}{c}3.840 \\
(15 \%)\end{array}$ & $\begin{array}{c}2.705 \\
(21.5 \%)\end{array}$ & $\begin{array}{c}4.288 \\
(34.9 \%)\end{array}$ & $\begin{array}{c}3.655 \\
(50.2 \%)\end{array}$ \\
\hline
\end{tabular}

The results above demonstrated the importance of ATMS ch. 1 at $23.8 \mathrm{GHz}$ to TPW retrieval over land as well. The MiRS retrieval system utilizes the information from all channels. Figure 1 shows both the positive sensitivity (Jacobean) to water vapor in the boundary layer and the negative sensitivity (Jacobean) to water vapor above the boundary layer in the MiRS help TPW retrieval, although ATMS ch. 1 alone cannot be used to derive TPW when the total sensitivity is close to zero (see Equation (7)). The positive sensitivity means that the satellite-measured brightness temperature increases with water vapor because the boundary layer emission is higher than the surface emission. The surface emission is the product of the surface emissivity by Planck function for the surface temperature. Oppositely, the negative sensitivity indicates the atmospheric emission above the boundary layer is less than the surface emission. The underlying physics is the sensitivity of the ATMS ch. 1 to the boundary layer water vapor is canceled by the sensitivity to water vapor above the boundary layer over the land, which prevents one from using Equation (7) to calculate the water vapor increment mathematically. Together with other ATMS channels in MiRS, the ATMS channel 1 can provide good sensitivity for retrieving water vapor in the boundary layer.

We notice that the impact values without using ATMS channel 1 on TPW are different over global (Table 2) and Continental United States (Table 3), in particular over land under cloudy conditions. The impact value depends on geographical regions because TPW and clouds depend on geographical regions as well. The global impact value (Table 2) is statistically representative. The conclusion is the same in that the TPW retrieval will be 
degraded without the ATMS channel 1 measurement. For comprehensive studies, more experiments to cover different seasons and geographies are definitely necessary.

\section{Discussion and Conclusions}

ATMS channel 1 at $23.8 \mathrm{GHz}$ has high sensitivity to TPW over oceans. Together with ATMS channel 2 at $31.4 \mathrm{GHz}$, the dual channels can be used to quickly estimate TPW and column cloud liquid water over oceans. The estimate is applied for quality control to satellite radiance assimilation at numerical prediction centers around the world. Over land, the ATMS channel 1 sensitivity is weak and, in some cases, close to zero, which prevents it from acquiring TPW in a single-channel retrieval. Thus, a comprehensive retrieval system like NOAA Microwave Integrated Retrieval System is used. This study found that the zero sensitivity at $23.8 \mathrm{GHz}$ on TPW over land is due to the cancellation of negative sensitivity in the upper atmosphere and positive sensitivity from the low atmosphere. The sensitivity itself in each atmospheric layer is meaningful and valuable. The MiRS can generate useful precipitation and water vapor profiles by utilizing information from ATMS channel 1 and other ATMS channels in which ATMS water vapor channels 18 to 22 have the weighting peaks between 300 and $800 \mathrm{hPa}$ [18]. The approach may be equivalent to water vapor slicing that is adopted from the concept $[19,20]$ of $\mathrm{CO}_{2}$ slicing for retrieval of the temperature profile. ATMS channel 18 provides good sensitivity for high atmosphere while ATMS channel 1 contains good sensitivity for low atmosphere. The cutoff of high vs. low is where the channel 1 layer sensitivity is zero, which mainly depends on surface emissivity. The state-of-the-art NOAA Microwave Integrated Retrieval System has been operationally acquiring geophysical parameters, including TPW. MiRS uses all ATMS channels to retrieve geophysical parameters simultaneously. Global statistics of the TPW retrievals shows that the performance over lands is degraded more than $12 \%$ without using channel 1. The statistics over CONUS show that the degradation is more than $15 \%$ without using channel 1 . Therefore, ATMS channel 1 is useful for acquiring TPW over oceans as well as over land.

Passive microwave signal is very weak and can be easily contaminated by radio frequency interference. The radio frequency interference from wireless communication, such as 5G, could affect the passive microwave remote sensing data used for weather forecasts and other applications [21]. The RFI will cause a positive bias and increase the noise. At present, it is unknown how many 5G stations there are and the operating frequency. It also depends on the antenna design because RFI to satellite depends on the antenna pointing direction and side lobes. In this study, the assessment of the impact on TPW is simply without ATMS channel 1 in comparison to with the channel 1. For a typical clear-sky case of U.S. standard atmosphere over land, the simulated radiance in the unit of $\mathrm{mW} /\left(\mathrm{m}^{2} . \mathrm{sr} . \mathrm{cm}^{-1}\right)$ for NOAA-20 ATMS channel 1 at $23.8 \mathrm{GHz}$ is $0.151925 \mathrm{E}-02$, more than four orders of magnitude lower than $0.102587 \mathrm{E}+03$ for the infrared channel M15 at $10.7 \mu \mathrm{m}$ of the NOAA-20 Visible Infrared Imaging Radiometer Suite (VIIRS).

Author Contributions: Conceptualization, Q.L. and C.C.; methodology, Q.L., C.G., Y.-K.L.; software, Y.-K.L.; validation, Y.-K.L. and C.G.; formal analysis, all authors; investigation, all authors; writingoriginal draft preparation, Q.L.; writing-review and editing, C.C., C.G., Y.-K.L.; All authors have read and agreed to the published version of the manuscript.

Funding: This work was supported by the NOAA under NA19NES4320002 at the Cooperative Institute for Satellite and Earth System Studies (CISESS) at the University of Maryland/Earth System Science Interdisciplinary Center (ESSIC).

Institutional Review Board Statement: Not applicable.

Informed Consent Statement: Not applicable.

Data Availability Statement: Not applicable.

Acknowledgments: The manuscript contents are solely the opinions of the authors and do not constitute a statement of policy, decision, or position on behalf of NOAA or the U.S. government. 
Conflicts of Interest: The authors declare no conflict of interest. The funders had no role in the design of the study; in the collection, analyses, or interpretation of data; in the writing of the manuscript, or in the decision to publish the results.

\section{References}

1. Boukabara, S.-A.; Garrett, K.; Grassotti, C.; Iturbide-Sanchez, F.; Chen, W.; Jiang, Z.; Clough, S.-A.; Zhan, X.; Liang, P.; Liu, Q.; et al. A physical approach for a simultaneous retrieval of sounding surface, hydrometeor, and cryospheric parameters from SNPP/ATMS J. Geophys. Res. Atmos. 2013, 118, 12600-12619. [CrossRef]

2. Liu, Q.; Weng, F. One-dimensional retrieval algorithm of temperature, water vapor, and cloud water profiles from advanced microwave sounding unit (AMSU). IEEE Geosci. Remote Sens. 2005, 43, 1087-1095.

3. Ferraro, R.; Weng, F.; Grody, N.; Zhao, L.; Meng, H.; Kongoli, C.; Pellegrino, P.; Qiu, S.; Dean, C. NOAA operational hydrological products derived from the AMSU. IEEE Trans. Geosci. Remote. Sens. 2005, 43, 1036-1049. [CrossRef]

4. Andersson, E.; Pailleux, J.; Thepaut, J.-N.; Eyre, J.-R.; McNally, A.-P.; Kelly, G.-A.; Courtier, P. Use of cloudcleared radiances in three/four-dimensional variational data assimilation. Q. J. R. Meteorol. Soc. 1994, 120, 627-653. [CrossRef]

5. Derber, J.; Wu, W.-S. The use of TOVS cloud-cleared radiances in the NCEP SSI analysis system. Mon. Weather Rev. 1998, 126, 2287-2299. [CrossRef]

6. Langland, R.-H.; Baker, N.-L. Estimation of observation impact using the NRL atmospheric variational data assimilation adjoint system. Tellus A 2004, 56, 189-201. [CrossRef]

7. Radio Frequency Interference (RFI) Workshop, ECMWF 2018. Available online: https://www.ecmwf.int/sites / default/ files/ elibrary /2019/19026-radio-frequency-interference-rfi-workshop-final-report.pdf (accessed on 29 January 2021).

8. English, S.-J. Numerical Weather Prediction, Assessment of the requirement for 23.6-24.0 GHz observations for weather forecasting. In Forecasting Research Technical Report; No. 440; ECMWF: Reading, UK, 2004.

9. Geer, A.-J.; Baordo, F.; Bormann, N.; Chambon, P.; English, S.-J.; Kazumori, M.; Lawrence, H.; Lean, P.; Lonitz, K.; Lupu, C. The growing impact of satellite observations sensitive to humidity, cloud and precipitation. Q. J. R. Meteorol. Soc. 2017, 143, 3189-3206. [CrossRef]

10. Gray, M. Public Weather Service Value for Money Review. Exeter. 2015. Available online: https://www.metoffice.gov uk/binaries/content/assets/metofficegovuk/pdf/about-us/what-we-do/public-weather-service/pws_value_for_money_ review_-_march_2015.pdf (accessed on 29 January 2021).

11. In Proceedings of the Final Acts World Radiocommunication Conference (WRC-19), Sharm el-Sheikh, Egypt, 28 October-22 November 2019. Available online: https:/ / www.itu.int/dms_pub/itu-r/opb/act/R-ACT-WRC.14-2019-PDF-E.pdf (accessed on 29 January 2021).

12. Woodhouse, L. Introduction to Microwave Remote Sensing; Taylor \& Francis: New York, USA, 2004; 370p.

13. Liu, Q.; Cao, C. Analytic expressions of the Transmission, Reflection, and source function for the community radiative transfer model. J. Q. Spectrosc. Radiat. Transfer. 2019, 226, 115-126. [CrossRef]

14. Lipton, A.E.; Moncet, J.-L.; Uymin, G. Approximations of the Planck Function for Models and Measurements into the Submillimeter Range. IEEE Geosci. Remote Sens. Lett. 2009, 6, 433-437. [CrossRef]

15. U.S. Standard Atmosphere 1976, National Oceanic and Atmospheric Administration, National Aeronautics and Space Administration, United States Air Force. Available online: https://ntrs.nasa.gov/api/citations/19770009539/downloads/19770009539.pdf (accessed on 29 January 2021).

16. Hewison, T.-J. Airborne measurements of forest and agricultural land surface emissivity at millimeter wavelengths. IEEE Trans. Geosci. Remote Sens. 2001, 39, 393-400. [CrossRef]

17. Karbou, F.; Prigent, C.; Eymard, L.; Pardo, J. Microwave land emissivity calculations using AMSU measurements. IEEE Trans. Geosci. Remote Sens. 2005, 43, 948-959. [CrossRef]

18. Liu, S.; Grassotti, C.; Chen, J.; Liu, Q. GPM products from the Mircrowave Integrated Retrieval System (MiRS). IEEE J. Sel. Top. Appl. Earth Obs. Remote Sens. 2017, 10, 2565-2574. [CrossRef]

19. Smith, W.-L.; Woolf, H.-M.; Hayden, C.-M.; Wark, D.-Q.; McMillin, L.-M. TIROS-N Operational Vertical Sounder. Bull. Am. Meteorol. Soc. 1979, 60, 1177-1187.

20. Menzel, W.-P.; Schmit, T.-J.; Zhang, P.; Li, J. Satellite based Atmospheric Infrared Sounder development and applications. Bull. Am. Meteorol. Soc. 2018, 99, 583-603. [CrossRef]

21. Witze, A. Global 5G Wireless Deal Threatens Weather Forecasts. Nature 2019, 577, V575. [CrossRef] [PubMed] 